\title{
A pedagogia da resiliência indígena em tempos de pandemia
}

\author{
La pedagogía de la resiliencia indígena en \\ tiempos de pandemia
}

Gersem BANIWA ${ }^{1}$

Resumo

Resumen

Este ensaio é resultado de um exercício reflexivo, pedagógico e filosófico da dura experiência existencial em tempos de pandemia, que exigiu uma revisitaçáo subjetiva ao mundo ancestral Baniwa. Foi apresentado no SemiEdu 2020 - Educação Intercultural e Direitos Humanos em Tempo de Pandemia. Trata-se de uma busca explicativa para a tragédia sanitária da pandemia da COVID-19 à luz das sabedorias e experiências Baniwa. Um achado aceitável é que se trata de uma reaçáo da natureza diante do antropoceno fora de rota e potencializada pelo homem que de manejador e mediador primordial passou a vilão da natureza e, com ela, da humanidade.

Palavras-chave: Pedagogias indígenas. Ancestralidade. Pandemia.

\begin{abstract}
Este ensayo es resultado de un ejercicio pedagógico y filosófico durante la dura experiencia existencial en tiempos de pandemia que requirió una revisión subjetiva del antiguo mundo Baniwa. El objetivo era buscar una posible explicación para la tragedia sanitaria de la pandemia COVID-19 a la luz de la sabiduría histórica y las experiencias de losBaniwa. Un hallazgo aceptable es que se trata de una reacción de la naturaleza ante el antropoceno fuera de ruta y potenciada por el hombre que, de administrador primordial y mediador, se convirtió en el villano de la naturaleza y, con ella, la humanidad.
\end{abstract}

Palabras clave: Pedagogías indígenas. Ancestralidad. Pandemia. 


\section{Considerações gerais}

A humanidade está atravessando um ciclo de pandemia muito sério. Desde a Declaração de Emergência em Saúde Pública de Importância Internacional feita pela Organização Mundial da Saúde (OMS), em 30 de janeiro de 2020, em decorrência da infecção humana pelo novo coronavírus (COVID-19), já amargamos uma cifra trágica de mortos e infectados. Próximo de completarmos um ano, já soma quase 250.000 mortes no Brasil e no estado do Amazonas se aproxima de 8.000 mortes. Entre os povos indígenas, de acordo com dados da Articulação dos Povos Indígenas do Brasil (APIB) aproxima-se de 1.000 mortos de uma população de 810 mil pessoas. Segundo dados da Coordenação das Organizaçóes Indígenas da Amazônia Brasileira (COIAB), no estado do Amazonas concentram os piores dados, 238 mortos (até 29 de janeiro de 2021). É importante esclarecer o uso de dados das organizaçôes indígenas aqui porque são muito mais confiáveis do que os dados oficiais do governo que são claramente incorretos, porque não consideram e não contabilizam mortes de indígenas residentes em terras indígenas não reconhecidas pelo governo e os residentes em centros urbanos que somam $43 \%$ da população indígena do Brasil. Este tratamento do governo é claramente discriminatório e ilegal, uma vez que a Constituição do país não faz nenhuma distinção entre indígenas residentes em territórios indígenas demarcados, não demarcados ou mesmo residentes em centros urbanos ou outros lugares.

Como podemos perceber,a tragédia está mais acentuada no Amazonas, o Estado que concentra $1 / 4$ da população indígena do Brasil. $\mathrm{O}$ novo coronavírus se espalha rapidamente por Aldeias. A falta de plano do governo, a presença de invasores nos territórios indígenas e a contrapropaganda criminosa sobre a vacinação implementada por igrejas fundamentalistas bolsonaristas junto às aldeias aumentam o drama. Contrário à demarcação de terras indígenas, o atual presidente da República repete desde sua campanha eleitoral sua vontade de autorizar atividades econômicas, como mineração e monocultura nos territórios indígenas, o que está encorajando um crescimento alarmante de invasóes de territórios indígenas. Assim, os povos indígenas têm que enfrentar ao mesmo tempo a Pandemia da COVID-19, as invasóes de suas terras, a perseguição e ameaças às suas lideranças, um governo hostil aos seus direitos e uma parcela racista da sociedade que é contrária à vacinação prioritária de indígenas.

$\mathrm{O}$ genocídio indígena no Brasil pode tornar-se uma realidade a qualquer momento, considerando que mais de 50 etnias ou povos indígenas contam com menos de 100 pessoas, 14 etnias/povos com menos de 50 pessoas e duas etnias contam com apenas três pessoas. Além destes, os mais de 100 povos indígenas isolados podem ser exterminados pela pandemia associados às invasóes de seus territórios, sem que a humanidade fique sabendo deles e de seus extermínios e exterminadores. 
Em muitas regióes do Estado o único meio de acesso a aldeias é aéreo. A doença se espalha por todos os meios: barcos, avióes e através das invasóes de terras por garimpeiros, madeireiros, fazendeiros, missionários e até mesmo por equipes de governos despreparados que adentram as terras indígenas mesmo à revelia das vontades dos indígenas. Existem aldeias que estão distantes a mais de 04 horas de vôo do hospital mais próximo. Na Amazônia são mais de 16 mil km de rios navegáveis e mais de 200 terminais hidroviários, que dificultam o controle de propagação da doença. É profundamente desumano ver aldeias indígenas inteiras sitiadas pela pandemia, pelos invasores de suas terras e por um governo hostil. Para piorar, muitos profissionais assalariados, como professores indígenas, tiveram seus contratos de trabalho cancelados pelos municípios e pelo Estado junto com a decretação da calamidade pública nacional e a suspensão das atividades de ensino nas escolas.

\section{Pandemia e povos indígenas}

Ciclos naturais ou sociais de epidemias, pandemias, enchentes, secas e outras formas de desastres naturais ou cósmicos sempre fizeram parte da história da humanidade, mas que se intensificaram após o contato, levados pelo homem branco, de formas deliberadas ou não. Segundo a cosmologia Baniwa, o mal, o caos, a desordem, assim como as doenças estão presentes desde a origem do mundo. O início do cosmo é uma sucessão de sangrentas lutas entre os proto-humanos e seres-espíritos não-humanos pelo controle do mundo. Essa guerra permanente, o caos e o não cumprimento de regras de convivência que imperavam no começo dos tempos inviabilizaram o estabelecimento de uma ordem social e natural que são apenas parcialmente controlados pelos seres que antecederam a humanidade (GARNELO, 2003). A irreversibilidade da morte e a perenidade de doenças são alguns dos eventos não controlados. Assim, a vida dos homens e, particularmente, dos xamãs é uma luta constante para conter e manejar as manifestações do caos e do mal e possibilitar a continuidade do cosmos e da vida humana e não-humana. Muitas doenças que acontecem hoje têm origem nas guerras do primeiro ciclo cósmico, guerras que, portanto, continuam. O caos, a desordem, as doenças e a maldade só não imperam em absoluto porque os heróis criadores deixaram um conjunto de instrumentos, práticas, rituais, saberes e fazeres para manejar e controlar as forças do mal e das doenças. O sistema cosmo, incluindo a natureza e a humanidade como partes inseparáveis, é potencialmente disruptivo.

Segundo a cosmologia Baniwa, não há promessa mágica ou apocalíptica de superação dessa disputa entre o bem e o mal. O que existe é a possibilidade de seu manejo e controle, razão que explica a importância dos conhecimentos e práticas 
tradicionais, sem os quais, o mundo mergulharia em profundo caos, desordem e império do mal denominado pelo xamã Davi Kopenawa de "queda do céu" (KOPENAWA, 2015). As possibilidades e condiçóes para o manejo e controle das forças do mal se encontram na natureza e no próprio homem. Ou seja, o manejo e o controle do mundo dependem da vontade da natureza e das condiçóes que ela oferece ao homem e este por sua vez de sua capacidade e vontade de cumprir o seu papel primordialmente estabelecido. O ser humano tem uma responsabilidade primordial na mediação entre as forças em disputa. Assim, a força de um desastre, de uma tragédia ou de uma epidemia ou pandemia natural ou social depende da capacidade de ação, reação, intervenção, atitude e comportamentos dos seres humanos, segundo princípios e orientaçôes primordiais.

$\mathrm{O}$ sistema de pensamento indígena Baniwa considera o universo em sua totalidade e o ser humano integrando a vida como um todo. A lógica indígena compreende a estreita e interdependente relação de todos os seres e coisas do cosmo. A natureza, enquanto território primordial de existência é a base das relaçóes. Tudo o que acontece no cosmo é resultado das relaçóes internas das quais os seres humanos organicamente fazem parte, seja por ação ou por omissão. Assim, o conceito de sindemia faz todo sentido e ganha profundidade quando se trata de experiências específicas em que a ação humana se torna ainda mais um agravante no evento, como é o caso da pandemia da COVID-19. Sindemia refere-se a um modelo de saúde que se concentra no complexo biossocial, ou seja, nos fatores sociais e ambientais que promovem e potencializam os efeitos negativos da interação de uma determinada doença (HORTON, 2020). Sindemia é um conceito cunhado por Merril Singer em 1990, para quem há a necessidade articulada de combater uma doença infecciosa e também ajudar a corrigir o contexto social das pessoas e comunidades, tais como combater a destruição da natureza, a profunda desigualdade econômica, educacional e ao mesmo tempo cultivar a sensibilidade, a solidariedade, o cuidado e o amor à vida e ao outro.

Richard Horton afirma que a vulnerabilidade dos cidadãos à COVID-19 permite concluir que o surgimento de um tratamento ou vacina protetora, por mais eficaz que fosse não seria suficiente. $O$ pesquisador argumenta que o avanço da doença deveria ser entendido então como uma sindemia e a busca por uma solução para a doença não deveria ser puramente biomédica, mas seria necessária maior atenção às doenças e à desigualdade socioeconômica, social e cultural. Em conclusão, Horton afirma que a menos que os governos elaborassem políticas e programas para reverter suas profundas desigualdades sociais e econômicas, o mundo nunca estaria verdadeiramente protegido de doenças.

Partindo da organicidade cósmica, do conceito de sindemía e do entendimento de que a COVID-19 pode ser considerada como uma reação da natureza à ação humana, como lição do cosmo aos processos ecocidas praticados pelo homem. 
Assim,,a COVID-19 é uma forte reação à ação destruidora do homem a tudo que está ao seu redor, horizontal e verticalmente, inclusive a si próprio. A doença foi potencializada no seu poder de letalidade e propagação, por meio da destruição da natureza, da vulnerabilizaçáo material e imaterial dos seres humanos e da instrumentalização dos cidadáos humanos quando são levados a agirem uns contra os outros, como no caso dos garimpeiros, madeireiros e fazendeiros agindo contra os índios, ou simplesmente por meio da minimização da doença e do enfraquecimento das políticas públicas para o enfrentamento da doença. mundo não é totalmente imprevisível. É previsível e sabemos que o que estamos fazendo, destruindo a natureza, nos levará certamente a mais tragédias, caos, desordens, doenças, e outros males.

As crises ou ciclos naturais não são casuais, são manifestações e lições que a natureza está nos dando. As pandemias fazem parte do tempo cósmico como expressão da necessidade e importância de levarmos muito a sério os princípios, valores, limites, sensibilidades e regras cósmicas, bem como os tempos, princípios e valores humanos deles emanados. As pandemias fazem parte dos processos e ciclos de transformaçóes do cosmo e junto,da humanidade. O vírus da COVID-19 é micro-organismo vivo da natureza que está tentando sobreviver, colonizando e usando o homem como seu reservatório de vida, porque o homem está destruindo seu habitat natural, a natureza. O ser humano é o predador e não o vírus. A natureza, em seu estado "natural" e sistêmico é manejável, controlável e provedora de vida e de existências. O ser humano é a parte da natureza cada vez mais destruidora, desordenadora e produtora de caos e maldades.

$\mathrm{O}$ ser humano moderno esqueceu sua tarefa primordial de manejador e mediador das forças em permanente guerra no mundo e vai se configurando cada vez mais como o principal causador da destruição e da autodestruição. Ele produz, provoca e potencializa o vírus, e ao fazer isso, póem em profundo risco a vida e existência do próprio ser humano, da natureza e do cosmo como um todo, porque perdeu o seu elo e toda conexáo com sua ancestralidade primordial e se lançou a uma aventura suicida de querer ter o domínio, o controle e a subjugaçáo altamente improvável da natureza, mas certamente desastrosa.

A perda de conexão com a ancestralidade cósmica, fonte de princípios de convivência e coexistência no cosmo comum, vem transformando o homem em vilão da história e de forma imprevisível e muito assustadora. A pandemia da COVID-19 revelou a tendência ontológica e social deste ser humano. Um ser humano frio, insensível, egoísta, materialista, que não dá ou dá pouco valor ao outro, à vida do outro. Pessoas pouco sensíveis que pouco se importam com a dor e o sofrimento do outro. Mais do que isso, um ser humano que não se comove ou pouco se preocupa com a morte, mesmo diante de muitas mortes. As pessoas que morreram e as vidas perdidas para sempre se transformaram em números a serem 
disputados, escondidos, minimizados ou mesmo desprezados. Nenhum exagero em denominar essa atitude de necropolítica, ou seja, políticas de morte. Política onde tudo importa, menos a vida e a morte de pessoas.

Essa insensibilidade com vidas e existências humanas se materializa entre pessoas comuns, mas principalmente entre os governantes. Para isso não foi preciso ir longe e nem muito esforço analítico, mas sentindo, vendo e acompanhando as atitudes das pessoas e as decisóes tomadas pelos governantes aqui na cidade de Manaus. Manaus, uma cidade com dois milhóes de habitantes foi atingida inicialmente em abril e maio de 2020 de forma trágica pela covid-19 e mais dramática ainda a partir da segunda quinzena de dezembro de 2020 na segunda onda. Imagens de frigoríficos abarrotados de mortos ao redor de hospitais, de enterros em massa e em valas comuns e de hospitais superlotados rodaram o mundo. A segunda onda foi ainda muito pior por conta da crise de oxigênio nos hospitais, na cidade e em todo estado, quando centenas de pessoas morreram asfixiadas em algumas horas. Muitas pessoas morreram nas portas de hospitais após horas de espera por um leito ou por uma bala de oxigênio. Com a notícia de superlotaçáo dos hospitais e falta de leitos muitas pessoas infectadas deixaram de procurar hospitais e morreram em casa e enterrados sem serem testados, e por isso, é provável que tenha havido um grande número de casos não registrados. Mesmo diante dessa tamanha tragédia os governos locais, Wilson Lima e Artur Neto e depois Davi Almeida não tiverem a sensibilidade e humanidade em tomar medidas necessárias, como lockdown ${ }^{2}$, por exemplo, para salvar vidas, como outros governos no Brasil e no mundo fizeram. Mesmo medidas leves tomadas como fechamento de comércio, bares, praças, balneários, igrejas, escolas, não foram cumpridas pela população porque os governos não foram capazes e competentes para fiscalizar e fazer valer as medidas. Atualmente já somam quase 8.000 mortes no Amazonas, com a média diária de 80 mortes por dia ascendente. Números absurdos, que poderiam ter sido evitados, pelo menos em boa tarde deles com medidas mais adequadas e responsáveis pelos governantes do Estado e do país que não tiveram sensibilidade e não deram valor às vidas das pessoas. Preferiram atender aos seus interesses financeiros para não perder arrecadação de impostos, para atender aos interesses dos ricos que náo querem perder suas margens de lucro e para atender ou não contrariar as vontades macabras dos lunáticos do Palácio do Planalto em Brasília e seus seguidores, que sempre minimizaram a doença, mesmo à custa de milhares de vidas humanas. Isso é imperdoável.

2 O lockdown: em português significa bloqueio total ou confinamento de pessoas e cargas e consiste em fechar uma região, interditando vias, proibindo deslocamentos e viagens não essenciais e obrigando as pessoas ficarem em suas casas e assim impor o isolamento social e conter a propagaçáo do coronavírus. 
Outro exemplo de insensibilidade e racismo do atual governo do Amazonas está relacionado às atuais 238 mortes de indígenas por covid-19, muitas delas poderiam ter sido salvas com um pouco de sensibilidade e responsabilidade. Muitas das mortes ocorreram por abandono e falta de assistência médica e hospitalar, nas aldeias e nas cidades. Muitas das vidas indígenas perdidas poderiam ter sido evitadas ou salvas se o governo estadual e a Assembléia Legislativa do Amazonas não tivessem revogado a lei estadual aprovada em 2018 que reservava $0,5 \%$ do orçamento anual do Estado (cerca de $\mathrm{R} \$ 65.000 .000,00$ ) para atender exclusivamente as demandas indígenas. Esse dinheiro fez muita falta no período da pandemia, e definitivamente poderia ter salvado vidas, apoiando hospitais na compra de oxigênio e, sobretudo, facilitando deslocamentos de pacientes e aquisição de materiais de proteção e de cuidados com higiene. Isso também é inadmissível e imperdoável. É muita desumanidade.

Outro exemplo de insensibilidade e pouco valor à vida das pessoas, foi demonstrado pelo presidente da república e sua equipe de governo que desde o começo da pandemia mostrou-se insensível e contrário a qualquer medida que fosse voltada ao enfrentamento da doença e nunca apostou em vacina nenhuma.

O processo de genocídio dos povos indígenas no Brasil é uma realidade patrocinada pelo governo federal, que se aproveita da pandemia para pôr em prática. O genocídio é eminente principalmente entre aqueles povos indígenas com números muito reduzidos de seus membros. Citamos como exemplo os casos do povo Juma que atualmente é composto por três pessoas e o povo Akurusú com 04 membros. Numa situação em que os três Juma sejam infectados pelo novo coronavírus, estes podem vir a óbitos e com isso o fim deum povo inteiro, de uma história, de uma civilização única, de uma língua, de um modo complexo e único de vida e de um sistema de conhecimento único - cosmovisão, ontologia e epistemologia únicas -, que desaparecem para sempre. Os povos indígenas vivem hoje um verdadeiro cerco de guerra, de ataques, de ódio e de profundo racismo. O genocídio é grave, é atentado contra a humanidade. Extermínio deliberado, parcial ou total, de uma comunidade, grupo étnico ou religioso, ou seja, destruição de populaçóes e povos.

O maior ato genocida do presidente da República foi estabelecer 16 vetos na lei que definiu medidas preventivas contra a covid-19 em comunidades indígenas, quilombolas e outros povos tradicionais durante a pandemia. O presidente vetou, entre outros pontos, a exigência de acesso ao fornecimento de água potável e distribuição gratuita de materiais de higiene, limpeza e de desinfecção para as aldeias indígenas. Vetou também a obrigatoriedade de o Executivo liberar verba emergencial à saúde indígena, instalar internet nas aldeias e distribuir cestas básicas. Outro veto presidencial foi o do dispositivo que exigia do governo criar condiçôes de flexibilidade a indígenas e quilombolas para acessarem o auxílio 
emergencial e que executasse açóes para garantir a essas comunidades a instalação emergencial de leitos hospitalares e de terapia intensiva, com o fornecimento de ventiladores e máquinas de oxigenação sanguínea.

Tais comportamentos, atitudes e posicionamentos dos dirigentes do país nos fazem perceber o quanto a nossa sociedade humana está à deriva, sem liderança e sem rumo. Neste vazio e vácuo sociopolítico é que imperam as profundas crises morais, éticas, ambientais, econômicas, religiosas. Crises de ordem civilizatória da humanidade, náo do mundo ou da natureza. As epidemias, as pandemias, as sindemias, os desastres ecológicos e ambientais e as pragas de gafanhotos que assolaram parte da América do Sul nos meses de setembro e outubro de 2020, são consequências, liçóes e respostas da natureza às açóes destrutivas do homem. Este cenário nos leva a pensar que o que estamos atravessando é uma triste e perigosa volta aos tempos remotos da barbárie. Uma civilização da barbárie, onde impera violência, truculência, líderes cruéis e sanguinários, deuses cruéis, ignorância, egoísmo, etnocentrismo, desumanidade, capitalismo selvagem. Vivemos tempos em que acontece à luz do dia um processo de radicalização e aprofundamento do ódio, do racismo, da intolerância e da violência.

\section{Pedagogias ancestrais e pandemias}

Como afirmamos, de acordo com a cosmologia Baniwa, o mundo é constituído por constantes e permanentes guerras entre as forças da natureza, realidade que demanda a necessidade de uma cultura cosmopolítica para o equilíbrio da vida. As relaçóes intracósmicas se sucedem de forma permanente e orientadas por princípios e regras primordiais, tais como reciprocidade, solidariedade, respeito, evitações, dádivas, regras alimentares, hábitos pessoais e coletivas de convivência cósmica, horários e contextos de banhos, formas de preparação, tipos e formas de alimentos -assados, cozidos, boiados ou transbordados, quentes, frios, requentados, feitos na hora, com sal, sem sal, com ou sem pimenta, pouca ou nenhuma gordura, dentre outras. Não se trata de sabor ao gosto, mas de regras condicionantes. O desrespeito e a desobediência a essas regras provocam reaçóes hostis das partes afetadas, por meio de desgraças como doenças, escassez de coisas e recursos, desastres, tragédias e mortes.

Este protocolo de convivência forma um conjunto de regras para possibilitar vida sustentável no mundo. Os heróis criadores ensinaram formas para evitar, equilibrar, manejar e superar as constantes desobediências e descumprimentos das regras de convivência e coexistência cósmica. Para cada ocorrência os humanos receberam ensinamentos de como enfrentar, manejar e superar a dor, o sofrimento e o sacrifício, por exemplo, por meios dos rituais de iniciação ou ritos de passagem 
da fase de criança para fase adulta. Tais ritos são precedidos de testes, provaçóes e privaçóes, como jejuar três ou mais dias sobrevivendo apenas com água e sob pesadas atividades de caça, pesca, coleta de alimentos silvestres na floresta, dentre outras. Imagina-se o que significa depois de três ou quatro dias de jejum, com energias levadas ao limite, o jovem ter que subir açaí, bacaba ou patauá, cujas atividades exigem muito esforço físico, e que mesmo em condiçóes normais, muitos não conseguem executar. Tudo isso para que fique gravado para sempre na alma, no coração e na memória do jovem iniciante de que a vida não é fácil, nem simples. Viver e viver bem requer sacrifícios e cultivos de forças, coragem, valores, hábitos e atitudes humanas especiais, como paciência, serenidade, solidariedade, reciprocidade, generosidade, espírito coletivo, familiar, comunitário, respeito ao próximo e à natureza para enfrentar os desafios inevitáveis e imponderáveis da vida e viver o mais feliz possível. A felicidade na vida depende da capacidade e habilidade em construir e praticar o caminho do respeito, da solidariedade e da reciprocidade entre os humanos e estes com a natureza e o cosmo. No momento mais sublime e forte do ritual de iniciação, em geral, um momento de maior sentimento de dor e sofrimento, os sábios anciãos que orientam e coordenam o processo ritualístico, proferem o seguinte conselho para o/a jovem: "Você está sentido a dor da fome, do cansaço, da pimenta ardente na boca, a dor do sofrimento. Pois bem, essas dores são potencialmente da vida. Você poderá e deverá evitar ou ao menos reduzir essa dor e sofrimento em você e nos outros ao seu redor, praticando a solidariedade, a generosidade, a hospitalidade, a partilha, a bondade. Entâo, nunca deixe sua/seu esposa/marido, seus filhos, familiares e visitantes com fome ou com sede e nem sem abrigo para descansar. Ao chegar um visitante, acolha-o com o coração, hospede-o e sirva-lhe alimento. Não esqueça que a vida é cheia de dor e sofrimento que só é superado com a prática da solidariedade, da partilha e do cuidado com o próximo. Seja solidário com todos, inclusive com a natureza. Nunca seja egoísta, escassa”.

Com este relato e testemunho objetivamos demonstrar, em primeiro lugar, como o povo Baniwa e os povos indígenas em geral, possuem referências existenciais para enfrentar desastres, tragédias e doenças. Em segundo lugar, e em consequência dos seus processos educativos aprenderam a enfrentar e superar momentos de profundas adversidades. Isso náo quer dizer minimizar ou ignorar a dor e o sofrimento, mas a capacidade de resistência e resiliência para enfrentar e superar as adversidades (LUCIANO, 2013). A tragédia da pandemia do coronavírus não é uma casualidade, é da ordem cósmica, portanto, previsível e evitável. Não foi evitada ou administrada pela incapacidade, incompetência e irresponsabilidade dos dirigentes políticos insensíveis, desumanos e anti-natureza. Por último, para demonstrar que toda ação ou reação ou contra-reação da natureza é sempre pedagógica, traz e oferece importantes liçóes e aprendizagens. Assim, 
o futuro do homem, da natureza e do cosmo também depende da capacidade humana de levar a sério as liçóes de dor e sofrimento da tragédia que devem ser entendidos como um rito pedagógico de passagem para se repensar e redirecionar os rumos que a humanidade perigosamente está tomando e pondo em grave riso a sua continuidade e a do cosmo.

Os ritos de iniciação funcionam como potência pedagógica da filosofia ancestral indígena que chegam até os dias atuais, revigorados pelas tragédias decorrentes da pandemia do novo coronavírus e do pandemônio político adotado pelos governantes. Os rituais de iniciação e outros rituais sociopedagógicos dos sistemas de conhecimentos ancestrais formam a fonte simbólica existencial da capacidade de resistência e resiliência tão marcantes entre os povos indígenas, verificados nesses tempos de pandemia, e tâo necessários para sustentabilidade da natureza e da vida, enfraquecida pela introduçâo do pensamento predador e anti-natureza do homem branco. Os povos indígenas estáo reaprendendo com a dor e o sofrimento pelas mortes de seus membros a valorizar e potencializar ainda mais seus valores ancestrais, como o profundo amor à vida, ao outro, à natureza, aos saberes tradicionais próprios, à solidariedade, aos modos de vida coletivos e comunitários. Reaprendendo a reconhecer e remanejar seus limites, mas também redescobrindo suas potências como no caso dos seus saberes no campo da medicina tradicional e mergulhando na realidade profunda em que vivem.

É assim que a força da solidariedade, a potência dos saberes tradicionais e as dádivas resultantes do profundo respeito à natureza estáo sendo essenciais e vitais para o enfrentamento da pandemia pelos povos indígenas, diante da ausência de políticas públicas e da omissão imoral dos governantes.

O tempo trágico da pandemia também propicia outras aprendizagens socioeducativas importantes sobre nós mesmos, sobre a nossa sociedade, sobre a nossa humanidade sobro o tipo de sociedade e humanidade que temos e estamos construindo. Descobrimos, por exemplo, as nossas fragilidades humanas como a pouca sensibilidade, o pouco respeito, o pouco cuidado e a falta de amor à vida das pessoas, manifestadas de forma muito clara por parte dos governantes e de uma parcela da população do Brasil e do mundo.

Descobrimos a enorme importância do Sistema Único de Saúde - SUS, como parte essencial de política de saúde pública no Brasil, gratuita, universal e de qualidade, que devemos defender com todas as nossas forças e meios legais e democráticos contra todas as forças políticas e econômicas conservadoras que estão sempre tentando enfraquecer, desestruturar e destruir, com o único propósito de deixar o povo sem assistência médica e forçar o trabalhador assalariado a aderir aos planos privados de saúde e aos hospitais particulares que cobram preços exorbitantes, inacessíveis aos povos indígenas e à grande maioria da população brasileira. 
Outra aprendizagem importante foi a comprovação clara dos limites da ciência e da tecnologia. Após um ano do surgimento do novo coronavírus até hoje a ciência médica não conseguiu desvendar a gênese e o funcionamento da doença provocada por ele e por isso mesmo ainda não possui o seu tratamento e cura e mesmo o com o início da vacinação muitas dúvidas, incertezas e desconhecimentos continuam sobre sua propagação e letalidade. É importante que este limite seja reconhecido, pois a ciência acadêmica historicamente se impóe como a dona do saber e da verdade e muita gente, como os povos indígenas, colocam tanta fé nela que acabam abandonando ou desvalorizando seus conhecimentos tradicionais e ancestrais como as medicinas tradicionais, por considerarem menos resolutivos. Afirmar que a ciência acadêmica não possui toda verdade não significa de forma alguma que náo tenha sua importância e relevância prática reconhecida, pois sabemos que inequivocamente a ciência acadêmica se tornou essencial e vital para o mundo de hoje e sem ela a humanidade e o mundo seriam muito pior do que temos hoje. Mas o que defendemos aqui é a necessidade de a Ciência Acadêmica reconhecer suas limitaçóes e sua necessidade de reconhecer outras ciências, outros saberes, igualmente relevantes, como são as Ciências Indígenas, porque também são resultados de experiências e vivências milenares que deveriam ser agregadas, somadas, complementadas e assim, ampliar as possibilidades concretas da humanidade no seu conjunto, enfrentar seus desafios nos campos ainda desconhecidos da vida e do mundo. Está na hora das distintas ciências existentes no mundo se juntarem em busca de respostas aos problemas enfrentados e ainda sem soluçóes, desvendar mistérios da vida e do mundo ainda desconhecidos e às perguntas humanas ainda sem respostas. Este projeto de pluralismo epistêmico da Ciência Acadêmica deveria ser a melhor e mais concreta resposta aos ataques negacionistas que está recebendo das forças políticas conservadoras no Brasil e no mundo.

A lição da humildade deveria ser estendida a toda sociedade humana, uma vez que esses tempos difíceis de tragédias provaram nossas fragilidades por meios de fortes sentimentos de medo, insegurança, dúvida, perda, finitude, incompletude, impotência, incapacidade, fragilidade emocional e existencial, necessidade de interação, de afeto, de solidariedade, de civilidade e de sensibilidade humana. Tais valores e sentimentos primordiais e ancestrais da vida vêm sendo gradualmente desvalorizados ou mesmo esquecidos e substituídos por outros sentimentos arriscados de prepotência e arrogância. Esta mudança filosófica e existencial parece estar associada à crença moderna na tecnologia e na máquina, como nos fala NuritBensusan (2020), com a qual concordo. A autora afirma que ignorar milhares de mortos em Unidades de Terapias Intensivas (UTIs), hospitais e cemitérios que poderiam ser evitados, seria uma forma de despistar nossa animalidade ou humanidade ou ainda esquecer nossa condiçáo ou limitação animal e humana. Assim, buscamos nos afastar da natureza para 
nos aproximarmos da máquina, com quem cada vez mais temos intimidade, companhia e ajuda, confundindo nossos cérebros com máquinas e esquecendo nossos corpos. Seria uma espécie de inveja da imortalidade e da ausência da dor e sofrimento das máquinas e fingindo superar tempos em que fugíamos de predadores subindo em árvores ou se escondendo em cavernas para nos tornarmos reféns ou vítimas do clima que alteramos, mas que não condiz com nosso sonho de sermos seres especiais. Bensusam conclui afirmando que a humanidade parece inclinar-se a apostar seu futuro e sua vida na tecnociência, no poder do dinheiro e nas vaidades individuais, incluindo, a nosso ver, as ideologias. Esse caminho nos levará, inevitavelmente, a novas pandemias, novos pandemônios, novos desastres ambientais e na continuidade e aprofundamento do racismo de todas as ordens e dimensóes e da necropolítica que estamos dolorosamente vivenciando.

As experiências com a tragédia sindêmica como a que estamos vivendo podem ser pedagogicamente e filosoficamente potencializadas como tempos de transformações, construções de novos ciclos e oportunidades de novas escolhas humanas para desviar e corrigir caminhos errados que vem tomando nos últimos anos. É uma oportunidade para a humanidade mudar radicalmente o seu conceito de vida, de existências e de desenvolvimento ao mesmo tempo em que processa novas aprendizagens de convivência e coexistência humana e cósmica. É também uma oportunidade para renovação e/ou reinvenção de princípios e protocolos de convivência e coexistência que ajudem na (re)construção de pessoas, famílias, aldeias, comunidades, povos, bairros, instituiçóes e cidades mais acolhedoras, solidárias, humanas, justas, igualitárias, inclusivas e sustentáveis. Mas, sobretudo, é uma oportunidade para (re)lembrarmos e nunca mais esquecermos que somos seres humanos integrados à natureza, portanto, sujeitos às suas leis para viver. Por isso, a pandemia é uma oportunidade de reaprender sobre a nossa espécie, revisitarmos nossas formas de estarmos e vivermos no mundo e repensar nossas relações entre nós e com a natureza (BENSUSAN, 2020).

\section{Direitos Humanos e Indígenas em Tempos de Pandemia}

Os direitos humanos são princípios e valores internacionais que servem para proteger, garantir e respeitar o ser humano; assegurar às pessoas o direito de levar uma vida com dignidade, liberdade e igualdade. São direitos reconhecidos a toda pessoa humana e que devem ser universais, isto é, se estender a pessoas de todos os povos e naçóes, independentemente de sua classe social, etnia, gênero, religião, nacionalidade ou posicionamento político.

Os Direitos indígenas são direitos específicos que reconhecem e garantem a continuidade étnica, cultural, linguística, ontológica e epistêmica dos povos 
indígenas, inclusive, os direitos originados dos costumes tradicionais específicos e diferenciados, denominados de direitos costumeiros ou direitos consuetudinários. Nosso entendimento é de que esses direitos, por suas relevâncias para a continuidade física e cultural dos povos indígenas, fazem parte dos direitos humanos, por isso, também são denominados de direitos humanos indígenas, ou seja, direitos que garantem aos indígenas suas humanidades específicas e diferenciadas. Além disso, em geral, os direitos indígenas são emanados e signatários dos direitos humanos. $\mathrm{O}$ avanço dos direitos indígenas foi possível dentro da luta pelos direitos humanos, destacadamente, os direitos a autonomia e autodeterminação, os direitos territoriais, os direitos à cidadania, os direitos à educação e saúde pública, os direitos linguísticos e outros.

Os Direitos humanos e os direitos indígenas ganharam espaço e importância no período pós II Guerra Mundial em meio a uma sociedade profundamente destroçada por atrocidades de duas grandes guerras em menos de 40 anos. A Declaração dos Direitos Humanos em 1948 representava a vontade de garantir a paz no mundo, combatendo toda forma de intolerância, racismo, violência, totalitarismo. De lá para cá, os Direitos Humanos contribuíram para o enfrentamento dos principais males da modernidade, tais como a miséria, a fome, o racismo, a desigualdade, a escravidão, o totalitarismo, o nazismo, o fascismo e outros.

Mas também se perceberam ao longo desse período os limites do alcance dos Direitos Humanos por suas próprias fragilidades programáticas e estratégicas. Em primeiro lugar, o respeito e o cumprimento dos Direitos Humanos dependem da vontade e da tutela dos Estados Nacionais que os criaram e subscrevem. Em segundo lugar, os Direitos Humanos estão fundamentados em direitos subjetivos, individuais, positivos, técnico-burocráticos. Além disso, ao serem concebidos e impostos como universalizantes e hegemônicos, os Direitos Humanos acabam ignorando e negando a diversidade humana cultural, as especificidades e diferenciaçóes de povos não ocidentais, inclusive, dos povos indígenas.

Na última década temos observado uma progressiva crise dos direitos humanos no mundo e, particularmente, no Brasil de forma muito preocupante, com o aumento do racismo, do ódio, da violência, da intolerância, do fundamentalismo, da desigualdade, da miséria e de ataques à democracia, à liberdade de expressão, à imprensa, à religiáo, aos direitos humanos e ambientais.

O racismo histórico-cultural-estrutural e a intolerância étnica são as violências que mais atingem e vitimam os povos indígenas, cujas origens pertencem às raízes cosmológicas, ontológicas e teológicas do ocidente europeu, herdeira das cosmologias judaico-cristâs, profundamente etnocêntricas, que sempre se autoproclamaram raças superiores, povos escolhidos por Deus e com o mandato de Deus deveriam se impor, subjugar, dominar, escravizar e converter, ainda que por meio da força da arma e da guerra todos os outros povos, raças e culturas. 
Foi a partir da cosmologia judaico-cristã que se propagou a dúvida da humanidade dos indígenas e dos negros, que justificou e fundamentou toda sorte de violência, racismo, intolerância, massacres e genocídios contra esses povos por não se encaixarem nas narrativas bíblicas sobre a criação do mundo e da humanidade de Adão e Eva e da refundação da humanidade a partir do dilúvio, do qual o único sobrevivente humano teria sido Noé e sua família, gerando toda a dúvida sobre a origem dos índios e dos negros, que no caso da história de Adáo e Eva, só poderiam ser herdeiros de Caim, filho mau de Adão e Eva. Mas em relação ao dilúvio, era inaceitável para os europeus admitirem que os indígenas das Américas e os negros da África fossem herdeiros de Noé, pois se assim fosse, cairia por terra todo o fundamento da superioridade dos povos brancos, uma vez que brancos, índios e negros teriam a mesma descendência, desde Adão e Eva.

A escola, enquanto invenção do ocidente europeu e como aparelho ideológico do estado sempre foi a reprodutora e disseminadora desta visão e prática racista, discriminatória, intolerante e extremamente etnocêntrica. Uma pesquisa encomendada pelo Ministério da Educação em 2016, revelou que 94,2\% de alunos, professores e técnicos de escolas brasileiras apresentavam preconceito contra pessoas ou grupos étnico-raciais e $95,3 \%$ gostariam de manter distância social dos índios (arquivo pessoal).

Há também outras formas de racismo, intolerância e violência contra os direitos humanos indígenas. Uma delas é a raiz econômica materialista que considera e propaga o índio culturalmente e economicamente do passado ultrapassado que se tornou empecilho para o desenvolvimento da civilização e da economia das sociedades dominantes capitalistas. O capitalismo enquanto teoria, ideologia e prática econômica é um dos principais vetores de violação dos direitos humanos no mundo de hoje ao supervalorizar e sacralizar o direito ilimitado de acumulação e consumo de bens materiais e imateriais por parte de indivíduos e grupos privados e das igrejas fundamentalistas da teologia da prosperidade em detrimento da coletividade, da economia solidária, da economia da suficiência e da sustentabilidade socioambiental.

Deste modo, os povos indígenas se tornaram problemas para as elites políticas e econômicas do sistema desumano do ultracapitalismo, que passam permanentemente a sofrer ameaças étnicas, identitárias e culturais por meio de perseguição racial, territorial, políticas integracionistas, perseguição às lideranças comunitárias e étnicas. Esse ambiente de ameaças e perseguiçóes alimentando o imaginário da sociedade, a visão do índio transitório que de algum modo, em algum momento deverá desaparecer consumando a extinção destes povos.

Diante de tudo isso, precisamos ter consciência ativa e reativa de que vivemos tempos difíceis em que uma parcela significativa da sociedade age contra a humanidade, contra a natureza, contra o meio ambiente, contra a razão, contra a 
ciência, enfim, contra o homem e a favor da barbárie, da violência, da ignorância. $\mathrm{O}$ Homem que desejou ser a medida de todas as coisas está sendo a (des)medida e (i) responsável pela instabilidade, destruição e ameaça ao planeta ou à espécie humana.

Em busca dos ideais da modernidade de igualdade, de liberdade e de fraternidade o homem provocou uma profunda e perigosa separação entre o homem e a natureza, separação esta que resultou na desconexão e destruição do elo primordial, holístico e orgânico da natureza (incluindo o homem) que sustenta o mundo cósmico. É urgente recuperar essa unicidade plural do cosmo do qual o ser humano é parte dependente, razão pela qual o seu corpo é a extensão do Grande Espírito, resumida por Viveiros de Castro (2015) como descontinuidade física e continuidade metafísica do ser humano indígena (VIVEIROS DE CASTRO, 1996).

\section{Considerações finais}

Diante de tanta insensibilidade e desumanidade da sociedade náo indígena, os povos indígenas reafirmam seus ideais de vida que se inspiram nos mais velhos, na ancestralidade de Bem-Viver, na reciprocidade e na profunda solidariedade entre as pessoas, na coletividade, na convivência com outros seres da natureza, no profundo respeito pela terra e no uso coletivo do que ela oferece, inclusive e principalmente fonte de tudo o que precisamos para viver e curar as doenças.

Nosso território, espaço onde vivemos, é lugar sagrado, lugar cheio de significados, de espiritualidades, de valores e de conhecimentos gerados ao longo da história que orientam a nossa existência, sendo imprescindível para a reprodução física e cultural e a segurança do presente e do futuro de nossos povos. Somos povos originários desta terra e vivemos com nossas identidades, cosmovisóes e epistemologias específicas e especial relação com os territórios que habitamos e com a natureza da qual fazemos parte e de quem somos dependentes.

Estamos entrando perigosamente numa era de epidemias, pandemias e sindemias como resultado da crescente perda e destruição da natureza praticada pelo homem. Estamos vivendo uma grave emergência climática que exige de nós coragem para tomadas de decisóes radicais para corrigir e mudar o rumo que estamos tomando. Para começar essa mudança de concepção e, consequentemente, de modos de vida, o primeiro passo é admitir que não é a natureza que está em crise e sim a humanidade que precisa urgentemente corrigir suas práticas e modos de vida predatórios e insustentáveis sob todos os aspectos: ambientais, sociais, econômicos, morais e éticos.

Em meio a esse pessimismo existencial global, nós povos indígenas, somos testemunhos vivos de que há outras formas de vida e outros modos de habitar o planeta comprovadamente sustentáveis. Nossos testemunhos e exemplos milenares 
de civilizaçóes altamente sustentáveis deveriam representar uma possibilidade real de ruptura com o atual sistema de vida global a caminho de um apocalipse trágico que se desenha, uma vez que vivemos há pelo menos 15 mil anos nessas terras baixas do nosso continente sem alterar a composição e o funcionamento dos ecossistemas, da biodiversidade e da Natureza-Mãe.

Somos testemunhos vivos da capacidade ancestral dos povos indígenas de lidarem com a doença, com a morte e com a dor porque sabemos lidar e nos entender com a natureza. Poderíamos arriscar a afirmar que para os povos indígenas, a pandemia não é a maior preocupação neste momento, mas a maldade dos seres humanos aglutinados em torno das elites políticas e econômicas, que potencializam a pandemia e dela se aproveitam para avançar em seus propósitos genocidas de extermínio dos povos indígenas, quilombolas, das comunidades tradicionais, dos pobres, dos idosos e a devastação do meio ambiente e da natureza como um todo.

A filosofia de vida dos povos indígenas, expressa por meio da utopia de Bem Viver é o caminho para uma vida saudável e sustentável no mundo. Bem viver é uma concepção de vida proveniente dos povos indígenas, segundo a qual não existe separação entre ser humano e natureza e como somos parte da natureza devemos viver de forma respeitosa e harmoniosa com ela. Segundo Magdalena León (2012), a teoria do Bem Viver "marca uma ruptura com a centralidade do indivíduo, a superioridade do humano e com as noçóes de progresso, desenvolvimento e bemestar capitalista" (LEÓN, 2012). Segundo Acosta (ACOSTA, 2016), o Bem Viver não é apenas uma alternativa, mas a única via que de fato pode se contrapor ao capitalismo e ao socialismo real comprovadamente excludentes e destrutivos com a diversidade de povos e com a natureza, porque traz a diversidade como fundamento.

Com essa esperança nossa missão cósmica se torna crucial e vital na (re) fundação e na (re)construção de novas humanidades e seres humanos, livres da maldição do capitalismo, do neoliberalismo e da teologia da prosperidade, da cosmologia de povo escolhido ou de filhos preditos e eleitos de Deus. Somos todos filhos de Deus. As pedagogias das resistências, das resiliências, das insurgências da vida e das existências, referenciadas em cosmologias ancestrais não coloniais, oferecem pistas e possibilidades reais para isso. Mas a missão é muito difícil porque requer mudanças radicais para enfrentar contextos e processos radicais. As escolas indígenas, por exemplo, com diferentes graus e matizes pedagógicos e curriculares estão longe de serem promotoras dessa refundação e reconstrução das atuais humanidades. Para serem, necessitariam iniciar por suas próprias refundaçóes de suas matrizes pedagógicas e curriculares a partir das cosmologias ancestrais, dos sistemas epistemológicos e ontológicos tradicionais e das lógicas socio cósmicas que regem todo o pensamento e os modos de vida dos povos indígenas. Isso significaria inverter toda a base organizativa, cognitiva, prática e 
funcional da escola indígena hoje, ainda muito centrada no pensamento e nos modos de vida dos colonizadores brancos.

O desvio da atual rota civilizatória é urgente, antes que seja tarde. Isso não é retorno ao passado, mas uma inflexão civilizatória em busca do equilíbrio, equação econômica, tecnológica capaz de garantir e tranquilizar o futuro de nossas futuras

geraçóes humanas e a continuidade do planeta por um bom tempo. É um desvio para o futuro, uma vez que na atual rota não tem futuro.

\section{Referências}

ACOSTA, A. O Bem Viver: uma oportunidade para imaginar outros mundos. São Paulo: Autonomia Literária Editora Elefante, 2016.

BENSUSAN, N. Manchete Socioambiental. Instituto Sociambiental, 2020. Disponível em: www.socioambiental.org - acesso em: 08 set, 2020.

GARNELO, L. Poder, Hierarquia e Reciprocidade: saúde e harmonia entre os Baniwa do Alto Rio Negro. Rio de Janeiro: Editora Fiocruz, 2003.

HORTON, R. Semanário da Revista The Lancet, setembro, 2020.

KOPENAWA, D. ALBERT, B. A queda do Céu Palavras: de um xamá yanomami. São Paulo: Companhias das Letras, 2015. 728p.

LEÓN, M. Redefiniciones econômicas hacia El Buen Vivir: um Acercamiento feminista. AWID, 2012.

LUCIANO, G. J. dos S. Educaçáo para manejo do mundo: entre a escola ideal e a escola real no Alto Rio Negro. Rio de Janeiro: Contra Capa; Laced, 2013.

SINGER, MC. Introduction to syndemics: a systems approach to public and community health. Jossey-Bass, San Francisco, 2009.

SINGER, MC and Clair, S. Syndemics and public health: reconceptualizing disease in bio-social context. Med Anthropol Q. 2003; 17: 423-441

SINGER, M, Bulled, N, Ostrach, B and Mendenhall, E. Syndemics and the biosocial conception of health. The Lancet 2017; 389(10072): 941.

VIVEIROS DE CASTRO, E. Os pronomes cosmológicos e o perspectivismo ameríndio. Mana vol. 2 no. 2. Rio de Janeiro, 1996. 